\title{
Using traffic data to estimate wildlife populations
}

\author{
Ing-Marie Gren ${ }^{1}$ • Tobias Häggmark-Svensson ${ }^{1}$ • \\ Hans Andersson ${ }^{1}$ - Gunnar Jansson ${ }^{2}$. \\ Annika Jägerbrand ${ }^{3}$
}

Published online: 26 November 2015

(C) The Author(s) 2015. This article is published with open access at Springerlink.com

\begin{abstract}
Wildlife populations are threatened worldwide by, among others, habitat fragmentation and hunting pressure. An important impediment for the large scale, national and regional, management of the populations is the difficulty to quantify population dynamics. The purpose of this study is to present a tool for such estimations which is based on available data in several countries; traffic load and traffic accidents with wildlife. An econometric model is developed, which accounts for landscape characteristics. It is applied to wild boar in Sweden, for which data on traffic load and accidents for different counties and years are available. Landscape characteristics are introduced with direct or indirect effects on population growth. The indirect landscape model gives the best statistical performance, and the results show relatively small differences in calculated intrinsic growth rate among counties but considerable differences in predicted population developments.
\end{abstract}

Keywords Traffic data - Wildlife population - Econometrics · Land scape characteristics $\cdot$ Wild boar $\cdot$ Sweden

JEL codes Q29 - Q57

\footnotetext{
$凶 \quad$ Ing-Marie Gren

ing-marie.gren@slu.se

1 Department of Economics, Swedish University of Agricultural Sciences, Box 7013, 75007 Uppsala, Sweden

2 Grimsö Wildlife Research Station, Department of Ecology, Swedish University of Agricultural Sciences, 73091 Riddarhyttan, Sweden

3 Environmental Unit, Swedish National Road and Transport Research Institute, Box 55685, 10215 Stockholm, Sweden
} 


\section{Introduction}

Wildlife populations, which we refer to as non-domesticated animals, are threatened by destruction of habitat (Woodroffe and Ginsberg 1998), killing for protection of agriculture where wildlife is viewed as a pest (Roemer and Forrest 1996), illegal hunting of wildlife (Treves and Karanth 2003), and the introduction of invasive species (Roemer et al. 2001). Approximately $50 \%$ of all the mammals worldwide are in decline and $25 \%$ are facing extinction (Pack 2013). However, wildlife species, including both carnivores and herbivores, create damages as predators on livestock and humans, and by eating and damaging crops in forest and arable land (e.g. Muhly and Musiani 2009). For example, in eastern and southern Africa, economic losses due to carnivores' predation on livestock can range from 1-25\% of potential revenue, and carnivores can severely reduce the quality of life (Bulte and Rondeau 2005). Unless properly managed, conservation of threatened wildlife species can be too successful and cause significant economic damage (Witmer et al. 1991). A major challenge for the management of wildlife populations is the difficulty to estimate and predict the population dynamics and size.

The purpose of this paper is to provide an econometric tool for the estimation of wildlife populations that makes use of traffic data, which are relatively easy to access in many countries. The tool is applied to the estimation of a population growth function of wild boar in Sweden. Wild boar are among the most wide spread mammals in the world, and the abundance has been increasing in many countries during the last decades (Massei et al. 2015). It is demonstrated how the tool can be used for predicting wild boar populations.

Wildlife population models are numerous in the ecological literature, with a variety of scopes and methods (see Munns 2006 for a review). Commonly used background data are; hunting statistics, capture-recapture, indirect indices, line-transect surveys of tracks or pellets, and direct observation at feeding sites (Acevedo et al. 2007). The most common approach to estimate ungulate populations on extensive areas, like counties or nations, has been to use hunting bags statistics. For example, this method was used by Boitani et al. (1995) who employed a catch per unit of effort method in an attempt to estimate the wild boar population in Tuscany (Italy). This approach does however require good information on the amount of effort put in capturing or killing the animals.

The problem of using hunting statistics for estimating population growth models is in many cases the difficulty of obtaining appropriate effort variables, such as number of active hunters and time spent on hunting. Therefore, this study develops a method for estimating population dynamics by using traffic data where changes in traffic accidents are assumed to reflect underlying population changes, and traffic load with wildlife is a measure of effort. This effort variable has an advantage compared with e.g. number of hunters since it reflects actual traffic by cars on the roads, and not just the number of cars which would be the correspondence to number of hunters. The relationship between traffic load and wildlife accidents has previously been described by Seiler (2004), who also pointed out the role of landscape characteristics. Similarly, Geisser and Reyer (2005) showed that an increased wild boar population density is correlated to traffic accidents, and that the population density to some extent depends on, and in 
some cases significantly related to, ecological factors. Our approach also allows for the estimation of impacts of landscape characteristics on growth of wildlife populations.

The theoretical basis for our approach rests on long term experiences from estimation of fish populations, with a common assumption of a logistic functional form (Schaefer 1954). To the best of our knowledge, the approach of using road kills to estimate population dynamics involving wildlife has not been applied by any earlier study. In our view, a contribution of this paper is thus the development and application of data on traffic accidents for approximating wildlife populations. We apply the model approach to estimate and predict wild boar populations in Sweden.

The paper is organized as follows. First, we present the theoretical framework for estimating wildlife populations based on data on traffic accidents and traffic load. Section 3 presents the application to wild boar population in Sweden. The paper ends with a summary and some tentative conclusions.

\section{The model}

Following the literature in fishery economics (e.g. Schaefer 1954; Kataria 2007), it is assumed that the development of a wildlife population over time in a region $i$, where $i=1, \ldots n$ regions, depends on population growth, traffic accidents, and hunting. The population growth is assumed to follow a sigmoid pattern described by a logistic function, which is written as:

$$
\begin{aligned}
\frac{\partial P_{t}^{i}}{\partial t} & =r^{i} P_{t}^{i}\left(1-\frac{P_{t}^{i}}{K^{i}}\right)-V_{t}^{i}-H_{t}^{i} \\
P_{0}^{i} & =\bar{P}_{0}^{i}
\end{aligned}
$$

where $P_{t}^{i}$ is population in period $t, r^{i}$ is the intrinsic growth rate, $K^{i}$ is the maximum population without any hunting and accidents, $V_{t}^{i}$ denotes individuals killed in traffic accidents, and $H_{t}^{i}$ is animals killed by hunting.

The population and its growth are not known, and a common approach has been to use catch per unit effort, i.e. where $H_{t}^{i}$ is divided by an effort variable, as an approximation of the latent population variable (e.g. Kataria 2007). Although data on killed animals is available in many countries, there is no appropriate data on harvest effort. We can therefore not use the commonly applied harvest or catch per unit effort to estimate the latent wildlife population. Instead, we relate traffic accidents to traffic load, $T_{t}^{i}$, and $P_{t}^{i}$, which is written as

$$
V_{t}^{i}=a^{i} T_{t}^{i} P_{t}^{i}
$$

From Eq. (2) we define accidents per unit traffic effort, $S_{t}^{i}$, which is used for subsequent analyses, as

$$
S_{t}^{i} \equiv \frac{V_{t}^{i}}{T_{t}^{i}}=a^{i} P_{t}^{i}
$$


However, landscape characteristics, $L_{t}^{i}$, are not accounted for in Eq. (1). In principle, these can enter the population dynamics in two ways; directly as an additional variable at the right hand side of Eq. (1) or indirectly through the impact on the intrinsic growth rate, $r^{i}$. In general, $r^{i}$ measures growth rate and determines the maximum population under ideal condition in absence of any regulatory pressure, such as hunting, traffic accidents or competition for food with other species. Landscape characteristics, which reflect habitat conditions, may be regarded as such a pressure. On the other hand, it can be argued that these characteristics determine the intrinsic growth rate and maximum viable population in a specific region, and would then enter Eq. (1) as determinants of the growth rate $r^{i}$. There is an old and large body of literature in ecology relating different types of species characteristics to landscape or habitat quality (e.g. Bender et al. 1998; Bean et al. 2014). It has been common to estimate the effects of landscape patterns on population abundance or survival, but not on population growth in a logistic modelling framework. Therefore, we have no priors on which formulation is most suitable and will therefore use both alternatives.

Direct impacts of landscape characteristics, $L_{t}^{i}$ which is a vector of landscape characteristics $j=1, \ldots n$ in region $i$, are formulated as effects on population growth according to

$$
\frac{\partial P_{t}^{i}}{\partial t}+H_{t}^{i}=r^{i} P_{t}^{i}\left(1-\frac{P_{t}^{i}}{K^{i}}\right)-a^{i} T_{t}^{i} P_{t}^{i}+f^{i} L_{t}^{i},
$$

where each coefficient $f^{i j}$ in the vector $f^{i}$ of landscape variables reflects the marginal impact on population growth of respective landscape characteristic.

A necessary assumption in our modelling is that a proportional change in population can be approximated by a proportional change in $S_{t}^{i}$. We then replace $P_{t}^{i}$ in Eq. (4) with $S_{t}^{i}$ in Eq. (3), and divide both sides of Eq. (4) by $S_{t}^{i}$, which gives

$$
\frac{\partial S_{t}^{i}}{\partial t} / S_{t}^{i}=r^{i}-\frac{r^{i}}{a^{i} K^{i}} S_{t}^{i}-a^{i} T_{t}^{i}\left(1+x_{t}^{i}\right)+a^{i} f^{i} \frac{L_{t}^{i}}{S_{t}^{i}}
$$

where $x_{t}^{i}=\frac{H_{t}^{i}}{V_{t}^{i}}$. The existence of two types of pressures but only one effort variable thus scales up the included effort variable, the magnitude of which depends on the ratio between animals killed by hunting and traffic accidents.

The derivative of the dependent variable with respect to $t$ is obtained by making a finite difference approximation according to

$$
\frac{\partial S_{t}}{\partial t}=\frac{S_{t+1}-S_{t-1}}{2}
$$

The regression equation for population growth with direct impacts of landscape characteristics is then specified as

$$
Y_{t}^{i}=\alpha^{i 1}+\alpha^{i 2} S_{t}^{i}+\alpha^{i 3} T_{t}^{i}\left(1+x_{t}^{i}\right)+\alpha^{i 14} \frac{L_{t}^{i 1}}{S_{t}^{i}}+, . .,+\alpha^{i n 4} \frac{L_{t}^{i n}}{S_{t}^{i}}+\varepsilon_{t}^{i}
$$


where $\varepsilon_{t}^{i}$ is the error term. The relation between the variables and coefficients in the regression Eq. (7) and the direct landscape effect model in Eq. (5) are described as

$$
Y_{t}^{i}=\frac{S_{t+1}^{i}-S_{t-1}^{i}}{2} / S_{t}^{i}, r^{i}=\alpha^{i 1}, \alpha^{i 2}=\frac{r^{i}}{a^{i} K^{i}}, \alpha^{i 3}=a^{i}, \alpha^{i j 4}=a^{i} f^{i j} \quad \text { for } j=1, . . n
$$

We can now calculate carrying capacity, $K^{i}$, and the marginal impact of landscape characteristics, $f^{i j}$, from (8) as

$$
K^{i}=\frac{r^{i}}{\alpha^{i 2} \alpha^{i 3}} \quad \text { and } f^{i j}=\frac{\alpha^{i j 4}}{\alpha^{i 3}}
$$

With respect to the indirect landscape effect specification, it is assumed that the intrinsic growth rate shows a linear dependence on landscape characteristics, $r_{t}^{i}=$ $b^{i}+c^{i} L_{t}^{i}$, where $c^{i}$ is a vector of coefficients and $L_{t}^{i}$ a vector of landscape variables $j=1, \ldots n$. This formulation implies that the intrinsic growth rate can vary over time if there is a change in any of the landscape variables. The wildlife population growth equation can then be written as

$$
\frac{\partial P_{t}^{i}}{\partial t}+H_{t}^{i}=\left(b^{i}+c^{i} L_{t}^{i}\right) P_{t}^{i}\left(1-\frac{P_{t}^{i}}{K^{i}}\right)-a^{i} T_{t}^{i} P_{t}^{i}
$$

Similar to the derivation of the direct landscape effect model, we replace $P_{t}^{i}$ with $S_{t}^{i}$ from Eq. (3) in Eq. (10) and divide by $S_{t}^{i}$, which gives the logistic function for the indirect landscape effect model as

$$
\frac{\partial S_{t}^{i}}{\partial t} / S_{t}^{i}=b^{i}+c^{i} L_{t}^{i}-\frac{\left(b^{i}+c^{i} L_{t}^{i}\right)}{a^{i} K^{i}} S_{t}^{i}-a^{i} T_{t}^{i}\left(1+x_{t}^{i}\right)
$$

The regression equation is then specified as

$$
Y_{t}^{i}=\beta^{i 1}+\beta^{i 2} S_{t}^{i}+\beta^{i 3} T_{t}^{i}\left(1+x_{t}^{i}\right)+\beta^{i 14} L_{t}^{i 1}+, \cdots,+\beta^{i n 4} L_{t}^{i n 4}+v_{t}^{i .}
$$

where $v_{t}^{i}$ is the error term, and $Y_{t}^{i}$ and $x_{t}^{i}$ are defined as in the direct model specification. The coefficients in regression Eq. (12) are related to the logistic model in Eq. (11) as

$$
\beta^{i 1}=b^{i}, \beta^{i 2}=\frac{r_{t}^{i}}{a^{i} K^{i}}, \beta^{i 3}=a^{i}, \beta^{i j}=c^{i j} \quad \text { for } j=1, \ldots, n
$$

where $r_{t}^{i}=\beta^{i 1}+\sum_{j=1}^{n} \beta^{i j 4} L_{t}^{i n}$. Carrying capacity is calculated from (13) as

$$
K^{i}=\frac{\beta^{i 1}+\sum_{j} \beta^{i j 4} L_{t}^{i j}}{\beta^{i 2} \beta^{i 3}}
$$


The differences between the direct and indirect model specifications of the impact of landscape characteristics appear in the estimates of the intercept and coefficients in Eqs. (7) and (12), in the intrinsic growth rate, and, hence, calculated carrying capacity. In the indirect model intrinsic growth rate and thereby calculated carrying capacity are affected by changes in landscape characteristics over time in a region, which is not the case for the direct model. Instead, landscape characteristics enter the population growth as an increase or a decrease in the population.

\section{Application to wild boar (Sus scrofa) population in Sweden}

Traffic accidents with wild boar in Sweden increased by $250 \%$ between 2003 and 2011 (NVR 2013; Jansson et al. 2012). However, according to Tham (2004) wild boars have existed in Sweden over thousand years, but were eradicated in the end of the seventeenth century. In 1723 they were reintroduced for hunting purposes on the island Öland in the Baltic Sea, east of Sweden. This caused protests among farmers and they were eradicated once again, but small populations were kept in enclosures. Current population increases are caused by the escape of some individuals in the 1970's.

\subsection{Data retrieval}

The data needed for estimating regression equations specified in Eqs. (7) and (12) are; traffic accidents, traffic load, animals killed by hunting, and landscape characteristics. In this study we make use of a panel data set on these variables which includes 13 counties with wild boar populations during the period 2003-2012. Data on traffic accidents with wild boar are obtained from NVR (2013), which is considered as relatively accurate. Since 1987 drivers are obliged by $\$ 40$ Jaktförordningen to report wildlife accidents and injured animals to the authorities.

Traffic load is measured in millions of kilometers driven in each county (Trafik Analys 2013). This statistical measure does unfortunately not include foreign traffic, which will underestimate the true amount of kilometers driven, and thereby overestimate the accident intensities. Pressure of traffic load on the population in a county is highly dependent on size of the county and the road network. Traffic load intensity can be related to road or county area. However, road area can be relatively small in counties with low population density and large areas, and the traffic load intensity would then be quite high. If wild boars are evenly spread in the counties, a more appropriate measure would be to relate traffic load to the county size, $T_{t}^{i}$, which is used in this study. Number of killed animals from hunting, i.e. $H_{t}^{i}$, is obtained from Viltdata (2014), which collects and compiles reports from hunting teams.

The landscape characteristics, $L_{t}^{i}$, included in this study are; areas of deciduous forests, Dec, boreal forests, For, pasture, Pas, arable land, Ara, and fences along the roads, Fenc. A deciduous component, specially beech (Fagus) and oak (Quercus), of the forest is appreciated by wild boars, and generally regarded to promote population development (Markström and Nyman 2006). Detailed data on tree species composition, i.e. here to discern the occurrence of these broadleaved stands, are however not 
available for the period under study why we confine the forest habitat parameter to separate only between deciduous and coniferous forest. Both pastures and arable land constitute important feeding sites for wild boar (Markström and Nyman 2006), and the distribution of such habitats may naturally influence their movements, especially crop fields in late summer (Jansson et al. 2012). However, although these habitats are attractive per se, the size and shape of such fields are also important, where small and narrow fields are preferred by wild boars rather than large open areas (Jansson et al. 2012).

It should also be recognized that deciduous forest, as well as other types of forests, may provide some difficulties for drivers to detect movements of wild boars in the landscape and thereby, ceteris paribus, increasing the probability of an accident but the problem is less accentuated for deciduous forest. On the contrary, arable and pasture land with a more open type of landscape tend to improve visibility thereby reducing the risk of an accident. However, a more open type of landscape would be less attractive to the wild boars that often tend to congregate in the intermittent area of forest and open landscape elements. Hence, we would expect a negative sign for the variables arable and pasture land.

In Sweden, supplemental feeding of wildlife, mainly ungulates, is allowed and extensively applied in many areas. For wild boar, this is part of the management (for hunting and/or to lure them from crop fields) and feeding stations are often frequently utilized and generally believed to promote its reproduction (Bergqvist and Pålsson 2010). Thus, we are well aware of that the extent (volumes and frequency) and distribution of supplemental feeding stations may confound the otherwise expected relationship between population development and habitat/landscape type, as well as influencing the local movements of wild boar. However, neither the number of feeding stations nor their positions are registered, why we in this study are not able to include them in our estimates. The estimates of the population dynamics will then be biased upwards for counties with relatively much feeding.

The variable for fences is measured as their length in relation to road kilometers, $F e n c_{t}^{i}$ and data are obtained from Bylund (2015). Descriptive statistics of all variables are presented in Table 1.

Except for Fenc, the landscape variables are quite stable across time. The variation is then explained by differences across counties. Construction of fences has increased in all counties, which raises the shares since road length has not changed.

\subsection{Regression equations and results}

Since the data set is a panel with observations for 13 counties over the period 20032012 we test for fixed or random effect model by a Hausmann test, and if a random effect model is statistically better than an ordinary least square estimate. The observed p-value of the Hausmann tests indicated that the null-hypothesis cannot be rejected, favoring a random effects model, see Table 3 in Appendix for presentation of results with these estimators.

However, tests revealed the existence of contemporaneous correlation among counties (Pesaran 2004). Cross-sectional dependence is likely to occur in a relatively small 
Table 1 Descriptive statistics ( $\mathrm{n}=130$ number of observations)

\begin{tabular}{lllll}
\hline & Mean & $\begin{array}{l}\text { Standard } \\
\text { deviation }\end{array}$ & Min & Max \\
\hline $\begin{array}{l}\text { Dependent variable } \\
Y, \text { annual rate of change in traffic accident intensity }\end{array}$ & 0.2517 & 0.2923 & -0.3604 & 1.0293 \\
Independent variables & & & & \\
$T$, traffic load divided by county size & 462,995 & 466,156 & 151,141 & $2,046,202$ \\
$V$, traffic accidents & 142 & 146 & 2 & 708 \\
$S$, accident intensity per traffic load & 0.0004 & 0.0005 & 0.000007 & 0.0024 \\
$H$, animals killed by hunting & 2913 & 2923 & 0 & 13339 \\
Ara, arable land/total area & 0.1898 & 0.0967 & 0.0597 & 0.4637 \\
Dec, deciduous forest/total area & 0.0037 & 0.0032 & 0.0003 & 0.0131 \\
Pas, pasture land/total area & 0.0345 & 0.0160 & 0.0056 & 0.0615 \\
For, forest land/total area & 0.5817 & 0.1137 & 0.3236 & 0.7667 \\
Fenc, fence length/ road length & 0.0126 & 0.0081 & 0.0001 & 0.0347 \\
\hline
\end{tabular}

country as Sweden where our units of analysis, counties, are subjected to the same type of national regulations and neighboring counties face similar weather conditions. If our independent variables do not reflect these cross-sectional dependencies the estimated standard errors will be affected. We therefore estimate our models with Driscoll and Kraay (1998) standard errors which are heteroscedasticity consistent and account for cross-sectional and temporal correlations.

It also turned out that all variables on landscape characteristics presented in Table 1 could not be included in the estimation due to multicollinearity. By removing Pas and For we obtained an acceptable mean variance inflation factor of 1.10 for the direct and indirect landscape models. The regression equations are then specified as:

Direct model:

$$
Y_{t}^{i}=\alpha^{1}+\alpha^{2} S_{t}^{i}+\alpha^{3} T_{t}^{i}\left(1+x_{t}^{i}\right)+\alpha^{4} \operatorname{Ara}_{t}^{i} / S_{t}^{i}+\alpha^{5} \operatorname{Dec}_{t}^{i} / S_{t}^{i}+\alpha^{6} F e n c_{t}^{i} / S_{t}^{i}+\varepsilon_{t}^{i}
$$

Indirect model:

$$
Y_{t}^{i}=\beta^{1}+\beta^{2} S_{t}^{i}+\beta^{3} T_{i t}^{i}\left(1+x_{t}^{i}\right)+\beta^{4} A r a_{t}^{i}+\beta^{5} D e c_{t}^{i}+\beta^{6} F e n c_{t}^{i}+v_{t}^{i}
$$

Regression results from the direct and indirect landscape effect models are displayed in Table 2.

All statistically significant estimates show expected signs in both models; the traffic effort variable including hunting $T(1+x)$ is negative, the accident intensity $(S)$ is negative, and the intercepts, the intrinsic growth rates, are positive. The landscape characteristics could have either sign. The significant coefficient of the share of arable land, Ara, has a positive sign in the direct and a negative in the indirect landscape effect 
Table 2 Regression results from the direct and indirect landscape effect models with Driscoll-Kraay standard errors, $\mathrm{p}$ values in parentheses

\begin{tabular}{lll}
\hline & Direct landscape effect model & \\
\hline Intercept & $0.307(0.029)^{* *}$ & Indirect landscape effect model $^{\mathrm{b}}$ \\
$\mathrm{T}(1+\mathrm{x})$ & $-0.122-7(0.008)^{* * *}$ & $0.547(0.001)^{* * *}$ \\
$\mathrm{~S}$ & $-78.058(0.201)$ & $-0.569-7(0.011)^{* *}$ \\
Ara & & $-166.283(0.004)^{* * *}$ \\
Ara/S & $0.055-3(0.049)^{* *}$ & $-0.352(0.004)^{* * *}$ \\
Dec & & \\
Dec/S & $-0.428-3(0.505)$ & $-0.532(0.944)$ \\
Fenc & & $-7.511(0.101)$ \\
Fenc/S & $0.243-3(0.619)$ & \\
Prob $>$ F & 0.000 & 0.000 \\
Adj. $\mathrm{R}^{2}$ & 0.125 & 0.118 \\
\hline
\end{tabular}

a Pesaran's test of cross sectional independence $=11.933$

b Pesaran's test of cross sectional independence $=11.074$

Significance level $* \mathrm{p}<0.1, * * \mathrm{p}<0.05, * * * \mathrm{p}<0.01$

model. A negative sign can be explained by relatively large areas of agriculture land without hiding opportunities for the wild boar in the landscape. Recall from equation (9) in Sect. 2 that the estimated coefficient of the direct landscape effect model is a combination of the coefficient of $T(1+x)$ and the coefficient of the landscape variables. Since the coefficient of $T(1+x)$ is negative the marginal impact of Ara is negative also in the direct landscape effect model.

The coefficient of Dec has a negative sign for the indirect landscape effect model and a positive marginal effect for the direct landscape model. The positive effect is expected. One reason for a negative effect can be the difficulty of avoiding traffic accident in forest areas because of the difficulty to see the wild boar in due time. However, the estimated coefficient of Dec is not significant in any regression model. The variable Fenc has the expected negative marginal impact on accident frequency in both models, but is significant only in the random effect model in Table 3 . The result indicates that the construction of fences has, in average, decreased the relative annual increment in accidents by approximately $8 \%$.

Unfortunately the models do not have a high $\mathrm{R}^{2}$ value indicating that some variation has not been accounted for. On the other hand, the F-values are significant at the $1 \%$ confidence level. However, descriptive statistics in Table 1 show that the explanatory variables are skewed. This may not pose a problem unless the residuals are not normally distributed, which can create problems for efficient and unbiased standard errors. We therefore carried out a Shapiro-Wilk test of normal residual distribution and the results showed that the hypothesis of a normal distribution could be rejected at the $10 \%$ level for the direct landscape model, but not for the indirect landscape model. In the following, we therefore present calculations and predictions of wild boar populations only for the indirect landscape effect model. 


\subsection{Calculation and prediction of wild boar populations}

Based on the regression results in Table 2 we can calculate population levels for the years 2004-2011 and predict future populations for a given value of $\bar{P}_{0}^{i}$. Population levels for the years 2004-2011, for which data on traffic accidents and load are available, are calculated by dividing $S_{t}^{i}$ with the estimated $\beta^{3}$ coefficients for each year and county. We present results for the average county in Sweden and for counties with the highest and the lowest population levels, Kronoberg and Västra Götaland, respectively (Fig. 1). Calculated population levels for all 13 counties in 2011 are presented in Table 4.

According to our calculations, the wild boar population shows in average an almost fivefold increase during the period 2004-2011, and amounted to 9740 animals in 2011. This corresponds to a total population of 126,620 in Sweden. When comparing the total estimate with the few existing other estimates for single years, it can be noted that the number of 40,000 animals in year 2005 suggested by Swedish Jägareförbundet (2010) is close to our calculation of 38,519 (an average of 2693 in Fig. 1). However, our calculation of 126,620 for 2011 is below the report of 150,000 by Jansson et al. (2012). It can also be seen in Fig. 1 that the number of animals increases fourfold in Kronoberg county and tenfold in the Västra Götaland county. The difference in relative growth is explained by the much lower population in 2004 in Västra Götaland county than in Kronoberg county

We also compare actual with predicted traffic accidents for the years 2012 and 2013 in order to evaluate the estimated growth functions. The predicted number of average accident in 2012 and 2013 model correspond to, respectively, 271 and 349, which give an average of 310. The actual numbers are 321 in 2012 and 273 in 2013, which gives an average of 297 (NVR 2013). The prediction for each year is thus not so accurate but the average is relatively close to the actual number of accidents. However, exogenous factors can cause this prediction to become inaccurate i.e. extremely harsh winters will cause the population to deviate from the prediction.

Based on the regression results in Table 2, and the calculated intrinsic growth rates and carrying capacities we can predict wild boar populations for a given value of $\bar{P}_{0}^{i}$ which are obtained for the year 2011 (Table 4). Starting with calculating the intrinsic growth rate, it is found from the intercept but needs to be adjusted as shown in Eq. (13). The calculated average intrinsic growth rate amounts to 0.48 , which is evaluated at the average value of the share of arable land which is the only significant estimate of the influence of landscape variables. The growth rate of 0.48 is the same as that obtained from age-structured models of a single population by Lemel and Truve (2008) and Jansson et al. (2012). However, due to differences in shares of arable land, the calculated intrinsic growth rate differs among counties and ranges between 0.39 and 0.52 (Table 4).

As shown in Eq. (13) in Sect. 2 we can calculate the carrying capacity for each county by dividing the growth rate with the product of the estimated coefficients of $S$ and $T(1+x)$ for the indirect landscape effect model shown in Table 2 This gives an average of 50,965 animals per county, which can vary between 40,910 and 54,557 among the counties (Table 4). Without any hunting and traffic accident pressure, the total 


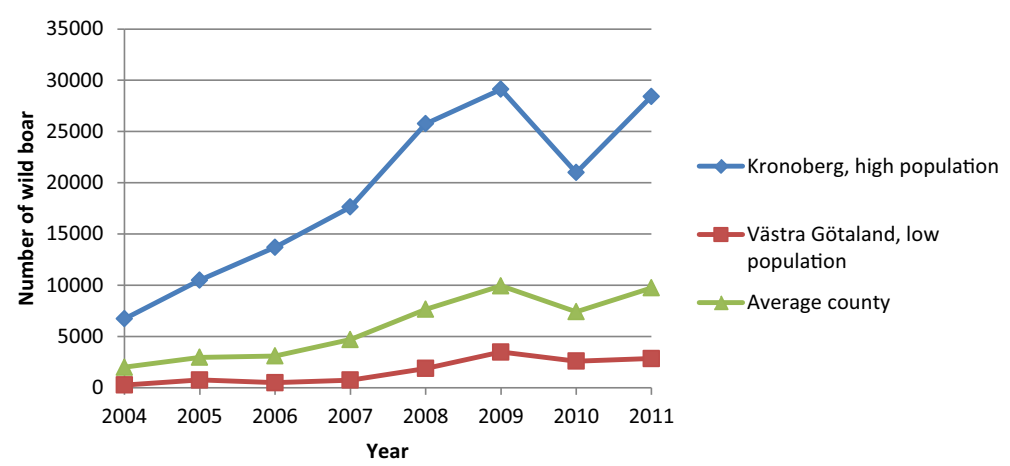

Fig. 1 Calculation of wild boar population over the period 2004-2011 in the average county, a county with initial high population (Kronoberg), and a county with initial low population (Västra Götaland) with the indirect landscape effect models. Sources Calculations based on Table 3 in Häggström-Svensson et al. (2014)

population could thus amount to approximately 663,000 animals, which corresponds to a fivefold increase from the calculated level of 126,620 in 2011.

Given the estimates of intrinsic growth rates, carrying capacities, and population levels in 2011 we can predict wild boar population in Sweden with assumptions of developments in traffic load, hunting, and landscape characteristics. According to Trafikverket (2014) the predictions for the next 20 years are modest or zero increases in passenger traffic by cars compared with the level in 2011. Landscape characteristics are likely to remain relatively stable over time, but hunting pressure may change depending on, among others, hunters' preferences and demand for wild boar meat. Due to these difficulties in forecasts, it is simply assumed that the future hunting and traffic accident pressure in relation to the population is the same as the average pressure over the period 2004 to 2011, which corresponds to 0.32 . The predicted developments of the populations over a 40 year period from 2011 for the three types of counties are then as displayed in Fig. 2.

In average, the population increases and reaches a steady level of approximately 17,200 animals in 2040. This implies a total steady state population of 223,600, which is a $77 \%$ increase from the calculated population level of 126,620 in 2011 . The developments differ among counties. Counties with relatively large populations will face a decline in the population and counties with low initial population meet an increase. The decline occurs since the pressure on a high population level is larger than the growth, and vice versa for counties with a relatively low initial population. This is illustrated in Fig. 2 for the Kronoberg and Västra Götaland counties. However, the calculated predictions are based on an equal relative pressure of 0.32 in all counties, which is a strong assumption. It is quite likely that the hunting pressure increases in counties with raising populations, and vice versa. The predicted steady state populations will then be lower in counties like Västra Götaland and higher in counties with large initial populations as in the Kronoberg county.

\section{Summary and conclusions}

The purpose of this study has been to develop a tool for calculating wildlife population dynamics based on availability of data on traffic load and accidents with wildlife. 


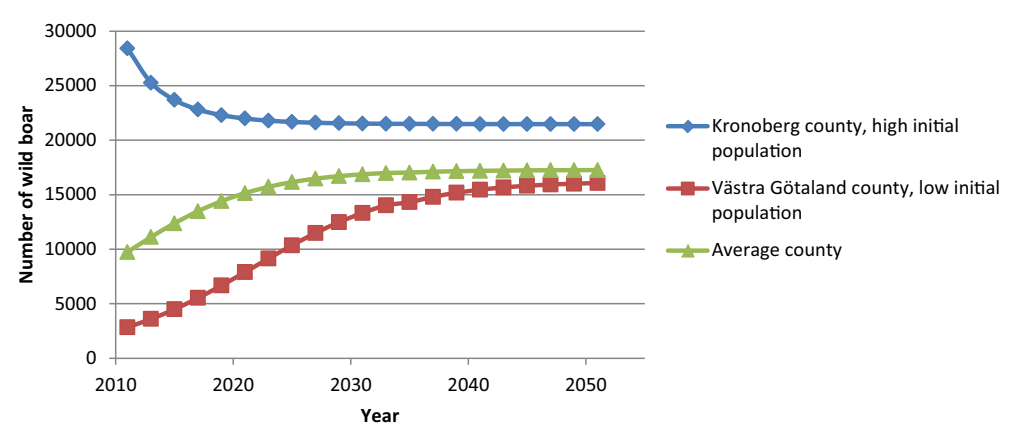

Fig. 2 Prediction of wild boar population in the average county, a county with initial high population (Kronoberg), and a county with initial low population (Västra Götaland) 40 years from 2011 with the indirect landscape effect model, and assumption of hunting and traffic accident pressure corresponding to 0.32 of the population

The main justification of the study is the lack of other data, in particular on hunting efforts. We developed regression equations for estimating intrinsic growth rates, carrying capacity, and impacts of landscape characteristics. Two types of impacts of the latter were considered; direct on the population growth and indirect through the intrinsic growth rate. A crucial assumption was that of a logistic functional form of the population dynamics. A necessary assumption was that the population growth rate can be derived from the traffic accidents per unit traffic load.

The model was applied to estimation of population growth functions for wild boar in Sweden, the traffic accidents of which have increased by $250 \%$ over the last 10 years. Using a panel data set over the period 2003-2012 for 13 counties we estimated population growth functions accounting for differences in landscape characteristics. The estimated intrinsic growth rates differed depending on the introduction of landscape characteristics; 0.31 if considered as a direct effect on population growth and an average of 0.48 if included as an indirect effect through the impact on the growth rate. The estimated average intrinsic growth rate with indirect effects is the same as estimates obtained by an age-structured model of a population on a small plot in Sweden (Lemel and Truve 2008; Jansson et al. 2012). However, the results from the direct landscape model did not fulfill the requirement of normal distribution of regression residuals. Calculations and predictions of wild boar populations for different counties were therefore made with the indirect landscape effect model. The results indicated an average increase of approximately $80 \%$ over the next 40 years if the average hunting and traffic accident pressure remain the same as for previous years. This average increase is unevenly distributed among the counties, where counties with large current population will face a decline and counties with low population will meet an increase.

However, the logistic function assumed in our study has been criticized because of the neglect of composition of population cohorts, assumption of constant intrinsic growth rate, proportional relation between population growth and pressure intensity, and disregard of stochastic shocks to the population (e.g. Clark 1990). Choices of other functions, such as age-structured models, might give other predictions of population developments. On the other hand, it would not be possible to estimate such functions 
based on actual traffic accidents and effort. Instead data would be needed on biological parameters such as reproduction and survival rates for different cohorts. As noted in the introduction, such data are most often non-existent at the large scale level. Nevertheless, our estimates of intrinsic growth rate of wild boar population in Sweden come close to results obtained from an age-structured model of a single population at a small plot.

Another factor that can bias the estimates based on our suggested approach is the existence of unreported traffic accidents with wildlife. According to Seiler and Folkesson (2006) the factor relating unreported to reported accidents involving damage to property amounts to 0.6 for moose and deer. Similar estimates are not carried out for wild boar. If the factor is in the same order of magnitude as for moose and deer, our calculations of wild boar population can be considerably underestimated.

Acknowledgments We are much indebted to the editor and an anonymous reviewer for valuable comments and to the Swedish Environmental Protection Agency for the funding of the project 'Economic analysis of the wild boar population in Sweden'.

Open Access This article is distributed under the terms of the Creative Commons Attribution 4.0 International License (http://creativecommons.org/licenses/by/4.0/), which permits unrestricted use, distribution, and reproduction in any medium, provided you give appropriate credit to the original author(s) and the source, provide a link to the Creative Commons license, and indicate if changes were made.

\section{Appendix}

See Tables 3 and 4.

Table 3 Regression results from the direct and indirect landscape effect models with the random and fixed effect models, $\mathrm{p}$ values in parentheses

\begin{tabular}{|c|c|c|c|c|}
\hline & \multicolumn{2}{|c|}{ Direct landscape effect model ${ }^{\mathrm{a}}$} & \multicolumn{2}{|c|}{ Indirect landscape effect model ${ }^{\mathrm{b}}$} \\
\hline & Random effect & Fixed effect & Random effect & Fixed effect \\
\hline Intercept & $0.307(0.000)^{* * * *}$ & $0.257(0.030)^{* *}$ & $0.546(0.000)^{* * *}$ & $0.725(0.271)$ \\
\hline $\mathrm{T}(1+\mathrm{x})$ & $-0.833(0.012)^{* *}$ & $-0.47-7(0.489)$ & $-0.569-8(0.078)^{*}$ & $-0.620-7(0.357)$ \\
\hline $\mathrm{S}$ & $-78.058(0.229)$ & $-137.177(0.174)$ & $-166.283(0.006)^{* * *}$ & $-157.35(0.135)$ \\
\hline Ara & & & $-0.351(0.246)$ & $-1.736(0.646)$ \\
\hline $\mathrm{Ara} / \mathrm{S}$ & $0.055(0.022)^{* *}$ & $0.044-3(0.160)$ & & \\
\hline Dec & & & $-0.532(0.954)$ & $42.731(0.448)$ \\
\hline $\mathrm{Dec} / \mathrm{S}$ & $-0.421-3(0.328)$ & $-1.231-3(0.099)^{*}$ & & \\
\hline Fenc & & & $-7.511(0.036)^{* *}$ & $-14.701(0.137)$ \\
\hline Fenc/S & $0.243(0.507)$ & $1.088-3(0.159)$ & & \\
\hline Adj. $\mathrm{R}^{2}$ & 0.125 & 0.069 & 0.118 & 0.059 \\
\hline $\begin{array}{l}\text { Prob }>\text { F or prob }> \\
\text { Chi2 } 2^{c}\end{array}$ & 0.0154 & 0.095 & 0.022 & 0.247 \\
\hline
\end{tabular}

\footnotetext{
${ }^{\text {a }}$ Hausman test of random vs. fixed effect model gave $\mathrm{p}=0.482$

${ }^{\mathrm{b}}$ Hausman test of random vs. fixed effect model gave $\mathrm{p}=0.978$

c Chi2 for the random effect models

Significance level $* \mathrm{p}<0.1, * * \mathrm{p}<0.05, * * * \mathrm{p}<0.01$
} 
Table 4 Calculated wild boar population in 2011, intrinsic growth rate, and carrying capacity for the 13 Swedish counties with established wild boar populations

\begin{tabular}{lrll}
\hline County & Population in 2011 & Intrinsic growth rate & Carrying capacity \\
\hline Blekinge & 3681 & 0.50 & 52,712 \\
Halland & 4481 & 0.47 & 49,600 \\
Jönköping & 5387 & 0.51 & 53,701 \\
Kalmar & 18,310 & 0.50 & 52,771 \\
Kronoberg & 28,416 & 0.52 & 55,146 \\
Skåne & 21,067 & 0.39 & 40,910 \\
Stockholm & 5591 & 0.49 & 51,949 \\
Södermanland & 14,199 & 0.47 & 49,578 \\
Uppsala & 4986 & 0.47 & 49,659 \\
Västmanland & 4648 & 0.52 & 54,557 \\
Va Götaland & 2841 & 0.47 & 49,915 \\
Örebro & 4773 & 0.49 & 51,689 \\
Östergötland & 8231 & 0.48 & 50,363 \\
Average county & 9740 & 0.48 & 50,965 \\
\hline Based on averag & & &
\end{tabular}

Based on average share of land use over the period 2003-2011

\section{References}

Acevedo, P., Vicente, J., Höfle, U., Cassinello, J., Ruiz-Fons, F., \& Gortazar, C. (2007). Estimation of European wild boar relative abundance and aggregation: A novel method in epidemiological risk assessment. Epidemiology and Infection, 135, 519-527.

Bean, W., Prugh, L., Stafford, R., \& Butterfield, H. (2014). Species distribution models of an endangered rodent offer conflicting measures of habitat quality at multiple scales. Journal of Applied Ecology, 51, 1116-1125.

Bender, D., Contreras, T., \& Fahrig, L. (1998). Habitat loss and population decline: A meta-analysis of the patch size effect. Ecology, 79, 517-533.

Bergqvist, G., \& Pålsson, S. (2010). Vildsvin skjuts på åtel - och är dräktiga i princip året om. Svensk Jakt, 9, 104-106.

Boitani, L., Trapanese, P., \& Mattei, L. (1995). Methods of population estimates of a hunted wild boar (Sus Scrofa L.) population in Tuscany (Italy). Journal of Mountain Ecology, 3, 204-208.

Bulte, E. H., \& Rondeau, D. (2005). Why compensating wildlife damages may be bad for conservation. The Journal of Wildlife Management, 69, 14-19.

Bylund, T. (2015). Data on fences and road length in different counties 2003 to 2014. Trafik Analys, Stockholm.

Clark, C. W. (1990). Mathematical bioeconomics: The optimal management of renewable resources (2nd ed.). New York: Wiley.

Driscoll, J., \& Kraay, A. (1998). Consistent covariance matrix estimation with spatially dependent panel data. Review of Economics and Statistics, 80, 549-560.

Geisser, H., \& Reyer, H. U. (2005). The influence of food and temperature on population density of wild boar Sus Scrofa in the Thurgau (Switzerland). Journal of Zoology, 267, 89-96.

Häggström-Svensson, T., Gren, I.-M., Ankdersson, H., Jansson, G., \& Jägerbrand, A. (2014). Costs of traffic accidents with wild boar in Sweden. Working Paper 2014:05. Department of Economcis, Swedish University of Agricultural Sciences, Uppsala, Sweden. Accessed October 27, 2014 from https://ideas. repec.org/p/hhs/slueko/2014_005.html.

Jansson, G., Månsson, J., \& Nordström, J. (2012). GPS-märkta vildsvin hjälper oss att förstå deras beteende. Svensk Jakt, 9, 96-98. 
Jägareförbundet (2010). Artpresentation - Vildsvin. Accessed April 25, 2014 from http://jagareforbundet. se/sv/Viltet/ViltVetande/Artpresentationer/Vildsvin/.

Kataria, M. (2007). A cost-benefit analysis of introducing a non-native species: The case of signal crayfish in Sweden. Marine Resource Economics, 22, 15-28.

Lemel, J., \& Truve, J. (2008). Vildsvin, jakt och förvaltning-Kunskapssammanställning för LRLRF. Svensk Naturförvaltning AB. Rapport 04.

Massei, G., Kindberg, J., Licoppe, A., Gacic, D., Šprem, N., Kamler, J., Baubet, E., Hohmann, U., Monaco, A., Ozolinš, J., Cellina, S., Podgórski, T., Fonseca, C., Markov, N., Pokorny, B., Rosell, C., \& Náhlik, A. (2015). Wild boar populations up, numbers of hunters down? A review of trends and implications for Europe. Pest Management Science, 71, 492-500.

Markström, S., \& Nyman, M. (2006). Vildsvin. Kristianstad Boktryckeri AB, ISBN 97-88660-44-3.

Muhly, T. B., \& Musiani, M. (2009). Livestock depredation by wolves and the ranching economy in the Northwestern U.S. Ecological Economics, 68, 2439-2450.

Munns, W. (2006). Assessing risk to wildlife populations from multiple stressor: Overview of the problems and research needs. Ecology and Society, 11, 23.

NVR (Nationella Viltolycksrådet Statistik). 2013. Accessed January 212014 from http://www.viltolycka. se/statistik/.

Pack, S. (2013). Comparison of national wildlife management strategies: What works where, and why?. Washington, DC: Heinz Center for Science.

Pesaran, M. H. (2004). General diagnostic tests for cross section dependence in panels. Cambridge Working Paper in Economics, 0435, University of Cambridge

Roemer, D. M., \& Forrest, S. C. (1996). Prairie dog poisoning in northern Great Plains: An analysis of programs and policies. Environmental Management, 20, 349-359.

Roemer, G. W., Coonan, T. J., Garcelon, D. K., Bascompte, J., \& Laughrin, L. (2001). Feral pigs facilitate hyperpredation by Golden Eagles and indirectly cause the decline of the island Fox. Animal Conservation, 4, 307-318.

Schaefer, M. (1954). Some aspects of the dynamics of populations important to the management of the commercial marine fisheries. Bulletin of the Inter-America Tropical Tuna Commission, 1, 25-56.

Seiler, A. (2004). Trends and spatial patterns in ungulate-vehicle collisions in Sweden. Wildlife Biology, $10,301-310$.

Seiler, A., \& Folkesson, L. (2006). Habitat fragmentation due to transport infrastructure. VTI Report 530A. Accessed April 25, 2015 from http://www.vti.se/en/publications/pdf/habitat-fragmentation-due-totransportation-infrastructure-cost-341-national-state-of-the-art-report-sweden.pdf.

Tham, M. (2004). Vildsvin - beteende och jakt. Stockholm: Norstedts.

Trafik Analys. (2013). Körsträckedatabasen. Accessed May 6, 2014 from http://www.trafa.se/vagtrafik/ korstrackor/.

Trafikverket (2014). Prognos för personresor 2030. Report no 2014:071, Borlänge.

Treves, A., \& Karanth, K. U. (2003). Human-carnivore conflict and perspectives on carnivore management worldwide. Conservation Biology, 17, 1491-1499.

Viltdata (2014). Accessed March 5, 2014 from http://www.viltdata.se/.

Witmer, G. W. \& DeCalesta, D. S. (1991). The need and difficulty of bringing the Pennsylvanian deer herd under control. Fifth eastern wildlife damage control conference (1991), Paper 45. Accessed October 13, 2014 from http://digitalcommons.unl.edu/cgi/viewcontent.cgi?article=1044\&context=ewdcc5.

Woodroffe, R., \& Ginsberg, J. R. (1998). Edge effects and the extinction of populations inside protected areas. Science, 280, 2126-2128. 